is but an aspiring, or (worse yet) an unaspiring, nebula instead of a glowing star in the educational firmament.

A fine, creative department is costly to maintain. A good engineering school spends more money on its productive educational work than it receives in tuition fees from its students, and any university chief executive who believes that a great engineering school can be run at less cost per capita of students than a great medical school, aside from hospital costs, is supporting an unfounded supposition. One fault attaching to our engineering education is that a few of the universities that support medical and various other branches of education on a high level of scholarly fitness are willing to see their engineering schools lie in the neutral space of semiprofessional, semiartisan activities, with minor emphasis given to scholarly and creative qualities. Naturally, such institutions fail to secure (or keep) scholarly men for leaders in their engineering work.
One more word: H. C. Bunner one time remarked, in a burst of characteristic humor, that Shakespeare "lived by writing things to quote." No one will gainsay either the greatness or quotableness of the great poet's writings, or deny that they are much quoted. So I will quote: "A jest's prosperity lies in the ear of him that hears it." That is a saying of truth and is worth remembering. We of this age may paraphrase that and say that a consulting engineer's repute lies in the minds of his clients, and a teacher's contributions lie in the achievements of his students. In these respects the engineer or teacher is but a catalyst and is not a direct factor in the reactions that occur except to stimulate them in the origin, to encourage them as they grow, and to give them range. It is having this in mind that gives me so deep an appreciation of the gift of the 1938 Edison Medal as a thoughtful token that something permanently serviceable has been accomplished.

\title{
Some Comments on
}

\section{Graduate Training for Engineers}

\author{
Representative industrialists and educators see value in postgraduate training in \\ some situations, but such training cannot be evaluated in advance in terms of indi- \\ vidual progress, nor is it in most industrial fields a substitute for actual experience
}

Q UESTIONING the value and adequacy of postgraduate engineering courses as commonly conducted, L. W. W. Morrow in an article in ELECTRICAL ENGINEERING for March 1939, pages 118-22, called for a program of investigation of postgraduate training. Solicited comments of some representative industrialists and educators are presented here.

\section{W. Smith member AleE}

Mr. Morrow has developed a number of questions and made many constructive suggestions regarding the objectives and achievements of graduate training for engineers which deserve careful consideration by those responsible for the planning and execution of this kind of educational work as well as those who are contemplating taking graduate work.

The inference that industry offers no special inducement to men with graduate training is no doubt justified to a large extent, although the value of such men for special advanced assignments like research work is

M. W. SмIтн is manager of engineering, Westinghouse Electric and Manufacturing Company, Pittsburgh, $\mathrm{Pa}$. generally recognized and appreciated by industrial management. The justification of a more general use of graduate engineers in industry will depend upon the extent to which their training can be planned and conducted to meet general industrial conditions and requirements. Industry will probably be slow to recognize graduate engineers as a special class for universal application, but as individuals having such training demonstrate its advantages through unusual or extraordinary accomplishments, the value of this kind of training will be appreciated just as other special training, fellowships, and so forth now supported by industry are recognized and successfully applied.

Graduate training is usually conducted along the lines of "more of the same" with the result that about all the student acquires is a greater accumulation of knowledge and information on the particular phase of the subject in which he specialized. This procedure and training, of course, makes the man a more valuable specialist and one who will probably advance more rapidly in his particular line of work.

Such a plan probably does not represent the fullest possibilities of graduate training nor fulfill all the needs of industry. The normal undergraduate training qualifies 
the student with average or exceptional ability to advance satisfactorily through the normal channels of specialized activity in an industrial organization, and it should be recognized that the normal forces of individual competition and demands for maximum efficiency of operation and output naturally tend to confine a man to a relatively limited field of activity in which he is likely to remain if his previous training is entirely of a specialized nature and if he does not broaden his education and qualifications through outside work and training. One of the problems with which industrial management is continually confronted is to find technically trained men with the qualification of leadership required successfully to direct the efforts and activities of others. The qualifications for leadership of course involve human characteristics, personality, and many other factors, but is it not possible that to some extent the deficiency may be influenced by limited views and perspectives resulting from education in restricted and specialized fields even though the training may be basic and fundamental? If this be true, then it would seem that there exists the possibility of enlarging or expanding graduate student training so that in addition to the usual specialized training which is required for the purposes and objectives of most courses, there should be an opportunity to plan and conduct the graduate work so as to broaden its scope in a way that will develop a better conception of the importance of and relation between the various branches of engineering and science. An understanding of more branches of science and an appreciation of their relationship will better prepare the student for observing and absorbing information relative to the varied over-all engineering operations of a particular industry and thus give those who are not content to remain in specialized activities a better opportunity to prepare for and undertake broader management responsibilities.

Because of its vital interest in the training of students, industry would welcome the opportunity to work with college faculties in the consideration and development of plans to broaden and improve the training for graduate engineers along the lines suggested by Mr. Morrow. This is a problem of mutual interest, and a closer relationship providing for a free exchange of ideas and experiences is certain to produce better results.

\section{A. R. Stevenson, Jr. fELLOW AIEE}

Mr. Morrow's excellent article is of great value in raising many questions which stimulate thought on the subject of "Graduate Training for Engineers." In a short space there is hardly time to discuss more than two phases of the subject.

1. A few colleges are now turning out doctors of philosophy in engineering that are valuable in industry as technical engineers. These colleges have at least one outstanding professor who, by his excellence in his profession and by his personality and character, attracts the

A. R. StEVEnson, $J_{R}$, is staff assistant to vice-president in charge of engineering, General Electric Company, Schenectady, N. Y. right kind of candidates and gives them training, inspiration, and an opportunity to develop.

According to well-established tradition, James A. Garfield is quoted as saying at an alumni dinner in New York City in 1872:

My definition of a university is Mark Hopkins at one end of a log and a student at the other.

This is the real crux of the situation. There is too much tendency today throughout both education and industry to put faith in false gods such as organization and facilities. These are important, but they are absolutely secondary and minor compared to the supreme importance of individual inspiration and leadership. Many colleges have put too much money in laboratories, in organization, in curricula, and in hosts of instructors, and then cannot afford to hire the one important element which would motivate the whole as the spirit motivates the body, a professor who is a great man.

The value of the degree of doctor of philosophy in the fields of physics and chemistry has been recognized more widely by industry than the same degree in engineering. The reason perhaps is that these fundamental sciences can more easily be practiced in a college laboratory. The science professors do researches which even though theoretical may be called practical in the best sense of the word because they lead to useful results. The graduate students associating with these professors get the stimulus of helping in real creative enterprises.

The necessity of such practical enterprises as a part of education is indicated in the following quotation from John Dewey's book "How We Think" :

The assumption that information which has been accumulated apart from use in the recognition and solution of a problem may later on be freely employed at will by thought is quite false. The skill at the ready command of intelligence is the skill acquired with the aid of intelligence; the only information which, otherwise than by accident, can be put to logical use is that acquired in the course of thinking. Because their knowledge has been achieved in connection with the needs of specific situations, men of little book-learning are often able to put to effective use every ounce of knowledge they possess; while men of vast erudition are often swamped by the mere bulk of their learning, because memory, rather than thinking, has been operative in obtaining it.

The doctors of medicine, law, chemistry, and physics get their stimulus largely from men who are practicing their professions.

Engineering has a tendency to deal with projects of such magnitude that it is hard to handle them in a laboratory. The teacher of engineering, therefore, is often not a practicing engineer who can stimulate his pupils by sharing with them real creative enterprises. Graduate work would be greatly benefited if the professors handling it could all be engaged part time in creative work.

2. We have all felt the disappointment of going on a vacation in search of happiness only to find the experience below expectation. Those who search primarily for security are the least likely to get it while the audacious adventurer is resourceful enough to gain security by his own wits. Many, indeed, are the examples of the philosophy that most worth-while things in life are obtained 
best as by-products of striving for some other more primary objective. It is true in engineering education. If the student's main objective is to learn, he can learn most and quickest by reading the work of others; the better it is explained, the fewer thoughts he need originate and the faster is his progress. That knowledge so gained is of little value to him later is recognized, but, if his primary objective is to obtain a useful result for someone, he may have to think enough to fix firmly the knowledge and the fundamentals for future use. A professor who is a current leader in engineering has such problems; he can by his own pre-eminent ability lead and challenge the brilliant student and finally, if he is a true leader, he can inculcate in the student a sense of moral and social responsibility toward mankind, an essential for those who are to shape our technical advance.

In conclusion: Correct graduate education is not primarily derived from well-equipped laboratories or from elaborately prepared curricula, but is a by-product of producing useful results in association with an inspiring leader of outstanding ability on some worth-while pioneering adventure.

\section{Melville Stein member AIEE}

Mr. Morrow appears to have taken a fair and square look at both sides of the question, and seems to conclude that engineering colleges should provide graduate training for engineers, provided the program is undertaken in the proper way and only after careful study and planning.

For most of the requirements of the Leeds and Northrup Company, preference is given young men who have spent four years in college and who are then put through the company's own graduate course, requiring approximately one year. However, for research work there is a need for men who have done graduate work in college although the graduate work need not necessarily be in engineering.

I agree with Mr. Morrow that it is difficult, if not impossible, to prove a case for or against graduate study in engineering. That being so, it would seem to me that an experimental approach would be the proper procedure. In other words, if graduate engineering courses could be established in a limited number of engineering colleges and a record were kept of the later achievements of the men taking these courses, a factual basis might be established for determining whether or not such courses are worth while.

As Mr. Morrow has indicated, most major technological advances are now being made by groups of workers rather than by individuals, and under such circumstances, it is a real question whether the best results would be obtained by physicists and engineers co-operating or by a group of superengineers working without the physicists. I am inclined to believe that the former is a better arrangement than the latter, but am willing to admit that the latter group might win out. In other words, it may be difficult to obtain in a single individual, even with extended train-

1. Melville Stein is director of research, Leeds and Northrup Company, Philadelphia, Pa. ing, the proper combination of the free imagination of the theorist and the more practical point of view of the engineer.

One thing that appears to be lacking in Mr. Morrow's presentation is a consideration of the response of the students themselves. He states that at least four years should be devoted to graduate study. May there not be a real difficulty in getting the type of man who would make a really good engineer, rather than a pure scientist, to spend eight or more years in training before taking up practical work? Perhaps the answer to this is that what is sought is not really a group of "superengineers," but rather a group of "supertechnologists" or possibly no existing terminology is adequate to label the ideal product of such graduate courses. In other words, a new name may be needed.

\section{O. W. Eshbach fellow AIEE}

Agreement with the analysis of the situation and idealism in objectives of graduate study for engineers as discussed by Mr. Morrow, does not justify an acquiescent amen. It implies a challenge to meet a situation which is by no means clearly understood. The paradox in it is that freedom of development of educational methods and facilities has been both the strength and weakness of current practice. One questions whether the opportunities to experiment have been fully grasped or whether unrecognized forces have limited choice and tended toward the development of a pattern that is characterized by expediency rather than ideal objectives. Certainly to judge whether graduate study is justified educationally on the basis of the character of industrial needs is adopting a poor criteria. It implies the act of following rather than leading.

One vital suggestion in the paper would seem a reasonable expectancy in so far as administrative action is needed. It is a decided effort toward better integration of what is now being done but even this implies objectives which are not easy to visualize. There is little doubt that in so far as undergraduate instruction is concerned there is need for a well-balanced and integrated program that permits greater flexibility in later choice of opportunity and at the same time would help to break down the popular conception that one must graduate in engineering with a special designation of proficiency in a traditional branch of engineering which is increasingly less prominent in creative work in life. If such a change could be effected gradually and soundly, the sequel to it would be a possibility of organizing graduate study along the more ideal pattern which Mr. Morrow suggests.

It would be unfair to imply that "learning more and more about less and less" characterizes present graduate study, but the danger is present and leads to personal restrictions likely to be interpreted to the detriment of much needed study in mature years. So long as facilities and conveniences for study while working are undeveloped

O. W. Eshвach is special assistant, personnel department, American Telephone and Telegraph Company, New York, N. Y. 
in fields of occupational usefulness, formal study of the type we now have is not far from the most practical, as distinguished from most ideal procedure.

\section{Robert E. Doherty member aieE}

Mr. Morrow's discussion of graduate work in engineering is the best I have seen. Its presentation of industry's narrow outlook upon the need for men with graduate training, of the discursive and shallow nature of much that is offered or given by colleges as graduate work, and of the inadequacy of faculty personnel fully prepared to lead study at high scientific level is, I think, fair; and I therefore agree that if we accepted present experience and practice as the sole bases for judging the case, we should have few reasons for planning graduate training.

But I also agree that we should look elsewhere for the guiding light. If colleges had been guided in the early stages of engineering education by the prevailing opinion of industry as to the need of college training, they would probably have concluded that work for the bachelor's degree was unnecessary or futile, and that even if some study beyond high school did seem worth while, it should be thoroughly "practical." One does not have to go back to beginnings to find this point of view; it still lingers unbelievably. The prevailing opinion of industry is not a competent guide as to whether high-grade graduate work in engineering is desirable, because very few industries know what it is to have full-fledged applied scientists around the place. I do not mean doctors of philosophy in chemistry or in physics or in any other single field of physical science whose training has hardly touched applied science. There are many of these in industrial and educational research laboratories, where they belong, and some of them are doing fine research jobs in uncovering basic scientific knowledge. Nor do I mean the usual engineering graduate, who certainly is, in a degree, an applied scientist; nor yet the masters of science in engineering, most of whom are, in this same degree, such scientists. I mean, as I understand Mr. Morrow means, men who really understand the basic principles and facts of those aspects of physical science that underlie a broad field of engineering, and who have cultivated intellectsdisciplined in those essential attitudes and techniques that will make it possible to deal effectively with knotty problems of applied science beyond the boundaries of precedent.

For light we should look not only inwardly, as Mr. Morrow suggests, but as well to a few industries where there are representatives of the kind of applied scientists we have in mind. A few industries have set up educational programs to train such scientists because they could not get them from colleges. To study the methods and experience of these would add greatly to, and I am sure would largely confirm, the idealistic concept of graduate study Mr. Morrow has portrayed. Moreover, if I may offer another illustration, not altogether without preju-

Robert E. Doherty is president of Carnegie Institute of Technology, Pittsburgh, $\mathbf{P a}$. dice, I would suggest that the program for the doctorate in electrical engineering at Yale University be examined. Whether it will accomplish the purpose for which it was designed is yet to be seen, but it was at least framed with definite end-objectives in view at each stage, and those objectives are almost precisely those Mr. Morrow has specified.

There are, however, two or three points in his plan on which I would comment. One is the extent of factual knowledge required at the start. This should be limited to the utmost minimum required to implement theory, or, as he says, "focus the abstract scientific knowledge." This minimum is still of very large scope, and to settle upon the minimum essentials in a rounded-out, integrated program is one of the most difficult educational problems I know. But it is solvable. It must be remembered in any study of this matter that the best place to acquire the specific facts of a specific job or problem is on the job. This lesson, by the way, is yet to be learned even in undergraduate work.

Another point is that "the man needed by technological industry must be able to state his variables at the start of a problem. .." If the problems are of the type I believe the author has in mind, I should regard this as optimistic. I've never seen anyone who could do it and know that he had stated them all at the start. But I agree that the more he can identify at the start, the better.

And finally, I think I probably see greater reason than he does for insisting on reasonable literacy regarding the interdependence of social and technological developments. I contend that unless we are content to give merely lip service to the theory of democracy, we should set down as a specification that professional men, especially those in science and engineering, should not be socially illiterate.

\section{R. W. Sorensen feLLOW AIEE}

Mr. Morrow's timely and comprehensive article presents almost every angle of the subject as expressed by many persons of varied experience and attitude toward education who were interviewed by him. Assuming that his title, "Graduate Training for Engineers," means a program of study and research carried on in residence at a technical college by men who have completed a regular four-year college course, I would like to supplement his paper by citing some observations and results within the scope of my own experience.

My first premise is that the art and science of engineering now have reached a stage where graduate schools for engineers are absolutely essential for the continuance of the engineering profession on the high plane it now has, and on the plane which we all desire and which is the goal of the four Founder Societies, the Engineers Council for Professional Development, the Society for the Promotion of Engineering Education, and the National Council of State Boards of Engineering Examiners.

If this point is well taken, the next question is, "Who

R. W. Sorensen is professor of electrical engineering, California Institute of Technology, Pasadena. 
should take graduate engineering courses and what subjects should be included in graduate curricula?" I believe that one-fourth or perhaps one-third the young men now graduating from four-year engineering courses should take at least one year of graduate work. The courses for those who take only one year of graduate work should not differ greatly as to type from the undergraduate upper-division courses of our better engineering colleges; that is, the one-year graduate curricula should include courses which enable the student to get well acquainted with special subjects such as long transmission lines, advanced work in the characteristics of electrical machinery, laboratory work of research nature, and to obtain increased facility in the use of differential equations and other advanced mathematics and physics as applied to engineering problems. If one-fourth to one-third of the engineering graduates from four-year courses continue for a year or more of graduate work, the undergraduate courses may also be improved by deferring some of the special technical subjects now given in the senior year to the graduate school and using the time thus made available in the undergraduate years for the humanities to an amount equal perhaps to 25 per cent of the total time available for study in the four undergraduate years. This may well be done to good advantage for all men taking engineering courses, because the undergraduate courses will still contain sufficient technical content to enable engineering graduates to carry on all the technical work involved in many phases of our profession and at the same time will give the four-year-course men a better general knowledge, thus better fitting them for many semitechnical and management positions than can be done by courses in which practically all the time of the undergraduate years is devoted to technical subjects.

Furthermore, the natural expectation is that the men who will take graduate courses are the men who because of their own desires and superior aptitude in the strictly technical phase of engineering have been encouraged by their teachers to take graduate work. My experience has shown that students mature very much more during their fifth year of work than during any of the four undergraduate years and that they obtain a well rounded grasp of the whole scope of what constitutes the work of an engineer, far in excess - as measured by time spent-of an added college year.

Graduate engineering colleges should also provide for a very select group of men of special ability three or four years of graduate work leading to the doctorate degree. The number of students who can qualify for and profit by this larger amount of graduate work probably is not more than five per cent of the number graduating from the four-year undergraduate engineering courses. Graduate curricula for such men should not be made up, to any great extent, of engineering courses designed to make men more proficient in the same type of technical work as that included in undergraduate courses, but rather the course work of graduate curricula for doctorate-degree engineers should be made up very largely of advanced courses in modern physics and mathematics, which with a bit of economics and chemistry coupled with "tie in" engineering courses and an engineering research problem, constitute a well rounded whole. In order to have such an arrangement function effectively, co-operation is absolutely essential between the science and mathematics faculties and the engineering faculties, so close that all departmental division lines are practically eliminated. Of course, it goes without saying that such a condition can exist only when the colleges concerned have outstanding science and mathematics departments sufficiently staffed by men who know what the engineer is trying to do and who are sympathetic with his program to care for the engineers who wish to take that work.

For 15 years I have had a part in assisting a considerable number of young electrical engineers through graduate engineering courses of this type. During that entire time - which also includes our recent depression years-the demand for men who have completed the work for their doctorate degrees has greatly exceeded the supply. Electrical engineers with doctorate degrees thus educated have been employed at premium starting salaries by colleges and by industry. In fact, the demand for such men and for the men who have completed one year of graduate work by industry has been so much greater than the California Institute of Technology graduates available that Mr. Morrow's statement- - "some manufacturing executives say it is foolish for engineering colleges to give graduate work"- - gives me no concern.

There is much more I would like to say regarding experiences in conducting graduate work, but to do so would make my discussion as lengthy as the paper.

My second premise is that the engineers who are the leaders in the profession at the time our present college men reach middle life will include many who have taken graduate work even unto the doctorate degree and that the next generation of engineers following these men will find graduate work almost absolutely essential to leadership, to the same degree as it has been so found by physicians, physicists, chemists, mathematicians, biologists, attorneys, and others, all of whom have found that the men occupying the better positions and enjoying the greater professional prestige are the men who for the most part have continued graduate work over a sufficient period to warrant the acquirement of a doctorate degree.

If Mr. Morrow's paragraph which reads as follows:

As a general conclusion we may say that present graduate work is without completeness or unity in plan or policy; is taught by overworked or incompetent teachers; is without adequate experimental facilities, has relatively few students enrolled and only a few of these are qualified to do the work. We have few reasons to base plans for graduate training upon present experience and practice. There are sound reasons, however, for studying the present situation and building upon the good things found in past experience.

in general is correct, I would like to call attention to the fact that there are a number of engineering colleges to which the statements in that paragraph do not apply. Those colleges have not tried to offer graduate work for large numbers nor have they provided graduate engineering courses until after outstanding science and mathematics departments with courses available to engineering students had been well established. After having thus provided 
these proper conditions for graduate work, the colleges I have in mind have established definite policies for graduate work which include unified and complete courses taught by competent and not overworked teachers provided with adequate experimental facilities in the way of laboratory space and equipment. To me it is perfectly clear that colleges which cannot arrange such a graduate program should not undertake engineering graduate work at all, or at least should not plan for more than one year of such work. I make the special classification regarding the one-year course because one year of graduate work, as has been stated, can well be along lines of the undergraduate engineering work, which does not demand correlated extensive graduate science and mathematics courses.

Particularly during the recent ten depression years a year of graduate work has had great value in making a way to employment possible for many men who could not obtain any satisfactory engineering positions at the end of their four-year courses, but who developed greatly during a year of graduate work and obtained at the end of their fifth year in college good engineering positions in places which seemed entirely closed to them at the time of graduation from the undergraduate courses.

\section{Leonard F. Fuller feLLOW AIEE}

Mr. Morrow's views are idealistic, as he says, and rightly so, for that attitude is required for progress in the complex problems of education. The continued interest of the engineering profession in the training of young engineers is necessary for the guidance of the educators upon whom rests the responsibility for final decisions in such matters. Because of his teaching experience, Mr. Morrow speaks from first-hand knowledge and impressions, and his ideas are worthy of the most thoughtful consideration. I hope his article will occasion widespread discussion among engineers and educators.

Surely there will be general agreement that graduate study should be under competent men; that the physical plant should be of the best; that it is desirable for teachers of engineering to be active in the practice of their profession; and that some instruction should be by professors in departments outside the college of engineering, such as physics and mathematics. Undoubtedly the training of both undergraduates and graduates should be rigorous and broad within reasonable limits, for excessive specialization produces the man frequently referred to as having learned so much about so little that he knows nearly everything about nothing. But I do not think our leading engineering schools are failing to meet the situation. Present conditions do not justify serious concern over the shortcomings Mr. Morrow mentions.

Let us examine the facts that support this viewpoint and in doing so let us realize that graduate training is merely one of many steps in the life of a successful engineer who will continue to study to the end of his days.

LEONARD F. FULLER is chairman of the department of electrical engineering, University of California, Berkeley.
His college training, undergraduate and graduate, is primarily for the purpose of teaching him how to study and how to think in the ways that generations of engineers have found necessary and best. If he masters the fundamentals of engineering technology and approach and learns how to make intelligent use of libraries and the information obtainable from other men, the student is equipped to proceed thereafter with further study under his own power in whatever direction the practice of his profession may require.

In well-organized graduate schools, students now have ample opportunity to work under the best men in the departments of mathematics, physics, and chemistry as well as of engineering. In leading colleges the limitations to the graduate training of engineers are not the lack of proper courses, or laboratories, or men. Nor are they to be found in the better students themselves except for the fundamental fact that graduate study cannot, even under the most ideal circumstances, take the place of and develop a man as will the experiences and responsibilities of actual practice. By this I mean that the strongest of faculties, having at its disposal the finest of laboratory and library facilities, could not train the most carefully selected and brilliant students to be well rounded engineers in 4 years or 40 years of graduate study. We must not overlook the human factors of the student himself. Engineering training reaches the saturation point for the best students after three or four years of graduate work following the bachelor's degree. For most students the saturation point is reached much earlier, depending upon the scholastic abilities of the individual, and for many it is reached before the end of a four-year curriculum. The young engineer must transfer from the school of engineering or science to the school of life and engineering experience for continued progress. If he is the right man and has it in him, he will develop as an engineer and a leader of men. If he does not possess the necessary qualifications, he will not advance. His college studies and degrees are not substitutes for performance in industry. Graduate study cannot make him an experienced engineer.

For these reasons industry cannot offer the young man with graduate training, no matter how fine it may be, a starting salary much higher than that paid the four-year graduate, but the superior training of the young engineer with an advanced degree, if he possesses other necessary attributes, will assist him to demonstrate superior ability to his employer and to advance more rapidly in his chosen profession.

\section{Karl T. Compton fellow aiee}

After reading Mr. Morrow's article on this subject, I immediately admit two personal reactions: (1) I very largely agree with his general thesis, though not with all of the opinions which he quotes; (2) there are many points in $\mathrm{Mr}$. Morrow's article which arouse in me an instinctive

KARL T. Compton is president of Massachusetts Institute of Technology, Cambridge. 
desire to discourse at length - a reaction which I shall hold in reasonable check. These reactions are a tribute to the stimulating character of the article.

Consider first the question of "market survey." Undoubtedly a survey of openings for engineers with postgraduate training is an important element in studying the desirable degree of participation by engineering schools in this aspect of engineering education. Such an analysis might show that the supply greatly exceeds the demand in mass, without proving that postgraduate work in some fields and for some types of men might not be the most important contribution which any engineering school could make. There are many situations, which can be easily called to mind, in which the employers are far behind the engineering educators in perspective and recognition of the opportunities and needs in industry. There are other cases in which this situation is reversed. The first point which I would make therefore is that any market analysis, to be of much value, would have to be carefully analyzed with reference to the needs and opportunities of particular situations by men whose vision is far beyond the average, and also that a detailed analysis and not a mere statement of average opinion or average conditions would be significant.

Certain facts of the real or potential market will, I think, be generally admitted. In some fields of engineering, as in the sciences, postgraduate training is now not only desirable but, for many kinds of work, is almost prerequisite. These are generally the types of engineering, like chemical, communications, and electrical, whose development on the heels of science has been most rapid. Other lines of engineering which have been more static, such as civil or mechanical engineering in their most common applications, are not so generally dependent upon more advanced academic training, and undoubtedly in a majority of cases practical experience at work is more valuable than postgraduate training in college except where the objective is some aspect of the profession which is more highly specialized, or developing more actively, or more dependent on mathematical and scientific background. If a mechanical engineer, for example, is to be a draftsman or a routine designer or operator of machinery, I see little value in graduate work; if he is to be an expert in fluid flow or strength of materials or the design and improvement of engines, then he can find in a good postgraduate department of mechanical engineering a great deal of valuable training which otherwise he could secure, if at all, only through disproportionate time and effort. My second point therefore is that the type of engineering activity toward which the student is headed (assuming his own inherent qualifications for this field) determines largely the degree of advantage of pursuing graduate work.

Another related consideration has to do with the organization of industry itself. In a highly organized industry like the telephone industry, the most valuable training for an engineer is probably in mathematics and physics, preferably including graduate work, and in the fundamentals of electrical engineering. The more specialized training for work in the company can be secured more competently and satisfactorily from the standpoint of the company after the young man has taken employment and through close association with the organized group of experts to which he is assigned. In a less highly organized industry however, such as the textile industry, there is relatively little opportunity for a young engineer to secure this type of specialized training from his associates, and here forward-looking educational institutions may provide training for certain advanced types of work far beyond anything likely to be available to the young employee in the industry. These facts again indicate that graduate training has a very important place to meet specific situations and that these situations may vary from decade to decade as industry develops.

Mr. Morrow stated that "there is a realization that the men now most active on the advance fronts of industry are the doctors in physics and chemistry." My observation has been that much of the most valuable research and training in the postgraduate engineering schools has been in the applications of physics and chemistry to the solution of engineering problems and the development of new engineering techniques. Extraordinarily satisfactory results have come from the infiltration of a few good research physicists or chemists into engineering departments where the co-operative attack on engineering problems jointly from the scientists' and engineers' points of view has been exceedingly fruitful. Graduate students, trained in such an atmosphere, have been found to be particularly valuable to industry in developmental work.

I have in mind a young man trained through postgraduate work as a mathematician and mathematical physicist, who then went on with postdoctorate study and research on the quantum theory of magnetism. In view of this highly theoretical background I was later very much interested to hear the head of the development laboratory of one of our great steel companies say that his people had secured more effective practical help from this young man than from any of their other consultants. I know of several other similar cases.

My conclusion is that postgraduate work in engineering can be exceedingly valuable for some situations and for some men. This is particularly true in the line of research and new development where no adequate alternative to postgraduate training exists. To some extent postgraduate training is also a practical necessity because the increasing demands for fundamental training in the sciences and the basic principles of engineering, combined with the enormously expanded scope of engineering knowledge, have made it necessary to go beyond the traditional four years of engineering education in order to secure a working knowledge of many branches of the subject.

If anyone really believes that there is not a market demand for engineers with postgraduate training, let him occupy for a while the presidential chair of an engineering school and talk to the continual succession of practical men from industry who come to request the establishment of specialized and therefore graduate courses in a far wider variety of subjects than any engineering school has considered it wise to undertake. 